\title{
Evidence-based follow-up in lung cancer?
}

\section{Focusing on the risk group of recently operated patients}

\author{
Caecilia Ng · Andreas Pircher · Florian Augustin · Florian Kocher
}

Received: 27 November 2019 / Accepted: 8 January 2020 / Published online: 23 January 2020

(C) The Author(s) 2020

\begin{abstract}
Summary In 2012 approximately 410,000 patients were diagnosed with lung cancer and about 353,000 lung cancer deaths were registered in the European Union. Although lung cancer is still the leading cause of cancer-related death worldwide, advances in detection and treatment have increased the likelihood of long-term survival. In patients receiving definitive curative treatment for lung cancer guidelines suggest follow-up of patients using clinical and radiological examinations over a certain period of time. However, standards differ and there are no generally accepted follow-up recommendations. Aim of this short review is to summarize the currently available knowledge and guidelines regarding surveillance of patients receiving definitive lung cancer treatment.
\end{abstract}

Keywords Lung cancer - Surveillance · Follow-up · Resection · Definitive treatment

\section{Background}

Lung cancer is amongst the most frequent cancer entities worldwide [1]. Patients with early stage disease might be cured by surgical treatment. And yet, disease recurrences are frequent in up to $30 \%$ of patients. To detect these cancer recurrences and to treat early and potentially curable relapses, cancer guidelines suggest follow-up of these patients using clinical

\section{Ng $\cdot$ F. Augustin}

Department of Visceral, Transplant and Thoracic Surgery,

Center of Operative Medicine, Medical University of

Innsbruck, Innsbruck, Austria

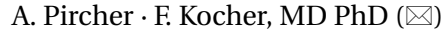

Department of Hematology and Oncology, Internal

Medicine V, Medical University of Innsbruck,

Anichstraße 35, 6020 Innsbruck, Austria

florian.kocher@i-med.ac.at and radiological examinations. However, no generally accepted follow-up regimens exist. There is an ongoing debate whether chest X-rays or CT scans should be used. Moreover, standards differ with respect to the timing of these examinations.

Lung cancer screening programs recently showed improved mortality rates for lung cancer patients [2]. The main effect of these programs was a considerable stage shift from UICC stage IV tumours towards UICC stage I tumours [3]. Therefore, lung cancer screening programs are expected to evolve within the next few years [4]. This will not only increase the number of potentially curable patients, but also the number of patients needing reasonable and effective follow-up strategies.

\section{Early postoperative follow-up}

After radical surgery, early postoperative complications are an important cause of early hospital readmission in lung cancer patients. According to a large Surveillance, Epidemiology, and End Results (SEER) program analysis, $12.8 \%$ of lung cancer patients receiving definitive surgery were readmitted to hospital within 30 days after discharge due to complications. Readmission was more likely in patients at higher age, after induction therapy, and in patients with preoperative comorbidities including congestive heart failure and chronic obstructive pulmonary disease. Moreover, patients with early readmission after pulmonary resection were at six-fold increased risk for death within 90 days [5]. In contrast to the study of $\mathrm{Hu}$ et al., Medberry et al. reported a readmission rate of only $4.3 \%$ in early stage lung cancer and primary surgical treatment [6]. Moreover, due to recent improvement of operative strategies, including minimally invasive approaches and limited anatomic re- 
sections, readmission rates decrease, as reported by Farjah et al. [7].

However, the poor outcome after readmission indicates that especially those patients at risk require intensified observation and early admission to intensive care units. Up to now, no recommendations for early follow-up after surgery exist. Especially in patients after induction treatment or with a high burden of comorbidity, including congestive heart failure and chronic obstructive pulmonary disease, a prolonged inpatient treatment and close outpatient observation might be beneficial to decrease early postoperative mortality.

\section{General surveillance remarks and prognosis after lung cancer recurrence}

Oncologic surveillance after initial definitive surgical treatment for lung cancer is only useful if the detection of disease recurrence leads to potentially life-prolonging interventions or curative therapy. Therefore, cancer follow-up only seems to be appropriate in patients who are deemed to tolerate further treatment interventions.

Lung cancer patients undergoing definitive surgical resection are characterized by a high rate of disease recurrence. It is estimated that only one third of patients have an isolated recurrence in the ipsilateral thorax and therefore might qualify for further definitive therapy [8]. According to another study, lung cancer recurrence with distant spread was observed in $29 \%$ of patients undergoing definitive surgery for non-small cell lung cancer (NSCLC) [9]. As a consequence, survival in operated patients with recurrence remains poor with a 5-year post-recurrence survival of approximately $15 \%[10,11]$.

With regard to second primary lung cancer, survival seems to be more favourable compared to recurrent disease. According to a study evaluating survival in patients undergoing surgical resection of metachronous secondary primary lung cancer, a 5year survival rate of $60 \%$ was reported. This result at least suggests that the detection of local recurrence or a metachronous primary lung cancer can lead to therapeutic interventions which might allow longterm disease-free survival [12].

Even though evidence on curative salvage options in recurrent disease is mainly based on retrospective studies, stage-adapted treatment algorithms comparable to primary lung cancer therapy are suggested. Therefore, in patients with isolated thoracic recurrence, comparable to a stage I or II pattern, further resection should be considered [13].

In patients who qualify for local curative salvage treatment, but surgical management is contraindicated, stereotactic radiotherapy represents a valid treatment option [14]. In recurrence similar to locally advanced disease (i.e. stage III) definitive multimodal therapy including radiotherapy and systemic ther- apy (chemotherapy and immunotherapy) should be performed $[15,16]$.

\section{Current guidelines}

Keeping in mind that the early detection of recurrence might lead to further potential curative treatment options constant surveillance is recommended by guidelines. According to the guidelines of the European Society of Medical Oncology [17]. Follow-up visits should be performed every 6 months for the first 2 years after curative treatment and should include history, physical examination, and chest CT scan at least at 12 and 24 months (level of evidence and grade of recommendation: IIII, A). Thereafter, further follow-up visits are recommended every 12 months in order to detect secondary primary tumors (III, B). In patients, suitable for salvage treatment options closer follow-up intervals with 6-monthly CT scans over 3 years might be suggested (III, B). In patients who do not qualify for definitive therapy in case of recurrence, follow-up visits might be tailored on an individual base $(\mathrm{V}, \mathrm{B})$. An important issue is also that all smokers should be offered smoking cessation programs. There are no recommendations for PET-CT in follow-up.

The National Comprehensive Cancer Network guidelines [13] suggest visits including history, physical examination and chest CT (optional contrast enhanced) every 6 months for 2-3 years after definitive surgical treatment for stage I-II lung cancer. Afterwards annual low-dose chest CT scans are recommended. In patients treated with radiotherapy for primary treatment of stage I-II lung cancer or in patients with stage III or oligometastatic disease undergoing curative treatment, history, physical examination and chest CT scans are recommended every 3-6 months for 3 years. The interval (3 vs. 6 months) of surveillance visits should be based on clinical decision making on an individual basis. Afterwards visits including chest CT scans ( \pm contrast enhancement) should be performed every 6 months for 2 years. After completion of 5 year follow-up, annual visits with surveillance by low-dose chest CT scans are suggested. Table 1 provides an overview of the current ESMO and NCCN guidelines.

\section{Randomized controlled trial evaluating a maximal surveillance algorithm}

Even though, surveillance is suggested by guidelines, the evidence to support these recommendations is poor. Only one randomized trial has evaluated different follow-up strategies so far. In the French IFCT0302 trial, including 1775 patients with completely resected lung cancer (pathological stages I-IIIA and T4 [pulmonary nodules in the same lobe] N0-2), two different follow-up strategies were evaluated [18]. 
Table 1 Surveillance guidelines after definitive lung cancer treatment

\begin{tabular}{|c|c|c|}
\hline \multirow[t]{6}{*}{ ESM0 [15] } & \multirow[t]{2}{*}{ General statement } & $\begin{array}{l}\text { Patients after treatment with curative intent should be followed for treatment-related complications, } \\
\text { tumour recurrence or occurrence of secondary primary lung cancer (III, A) }\end{array}$ \\
\hline & & Patients should be offered smoking cessation (I, A) \\
\hline & Year 0-2 & $\begin{array}{l}\text { H\&P + chest CT (preferably contrast enhanced, at least with contrast enhancement after } 12 \text { and } \\
24 \text { months) every } 6 \text { months (III, B) }\end{array}$ \\
\hline & $\begin{array}{l}\text { Patients suitable for salvage } \\
\text { therapy }\end{array}$ & Chest CT every 6 months for the first 3 years (III, B) \\
\hline & $\begin{array}{l}\text { Patients not suitable for salvage } \\
\text { therapy }\end{array}$ & Frequency of follow-up visits might be tailored on an individual basis $(V, B)$ \\
\hline & After 2(-3) years & H\&P + chest CT every 12 months (III, B) \\
\hline \multirow[t]{7}{*}{ NCCN [13] } & \multirow[t]{2}{*}{ General statement } & Smoking cessation advice, counselling and pharmacotherapy are suggested \\
\hline & & $\mathrm{PET} / \mathrm{CT}$ or brain MRI is not routinely indicated \\
\hline & \multirow[t]{2}{*}{ Year 0-2(-3) } & $\begin{array}{l}\text { Stage I-II (definitive surgical treatment } \pm \text { chemotherapy): H\&P + chest CT ( } \pm \text { contrast enhancement) every } \\
6 \text { months }\end{array}$ \\
\hline & & $\begin{array}{l}\text { Stage I-II (treatment by radiotherapy), stage III, stage IV (oligometastatic): H\&P + chest CT ( } \pm \text { contrast } \\
\text { enhancement) every 3-6 months (for } 3 \text { years) }\end{array}$ \\
\hline & \multirow[t]{2}{*}{$2(-3)-5$ years } & $\begin{array}{l}\text { Stage I-II (definitive surgical treatment } \pm \text { chemotherapy): H\&P + chest CT (without contrast enhancement) } \\
\text { every } 12 \text { months }\end{array}$ \\
\hline & & $\begin{array}{l}\text { Stage I-II (treatment by radiotherapy), stage III, stage IV (oligometastatic): H\&P + chest CT ( } \pm \text { contrast } \\
\text { enhancement) every } 6 \text { months }\end{array}$ \\
\hline & After 5 years & $\mathrm{H} \& \mathrm{P}+$ chest $\mathrm{CT}$ (without contrast enhancement) every 12 months \\
\hline
\end{tabular}

In the control arm follow-up consisted of clinical examination and chest $\mathrm{x}$-ray, whereas in the experimental arm patients underwent clinical examination chest x-ray, chest and abdominal CT scan plus bronchoscopy (which was an optional procedure in patients with adenocarcinoma). In both study arms surveillance visits were performed every 6 months after randomization during the first 2 years, and annually thereafter until year five. The primary endpoint was overall survival (OS). After a median follow-up of 8.7 years no significant difference in OS was observed (Hazard ratio 0.92, 95\% confidence interval 0.8-1.07, $p=0.27$ ). Disease-free survival rates at 3 years were 63.3 and $60.2 \%$ in the experimental arm and the control arm. The 8 year overall survival rates were 55.6 and $51.1 \%$, respectively. The authors concluded that a longer follow-up might be necessary to potentially detect a long-term overall survival benefit in the CT scan cohort. The primary endpoint was negative; nevertheless the study could identify some important aspects that might support intensive surveillance as an earlier diagnosis of recurrences and 2nd primary cancers could be identified. Some potential longterm benefits from CT-scan based surveillance was also that more surgeries were performed in the CTbased arm.

From a personal perspective, it seems that the intensive CT-based screening supports the notion that candidates at high risk for 2nd primary cancers are optimal candidates for CT screening.

\section{Potential harms of lung cancer surveillance}

Considering that the only randomized trial comparing a maximal surveillance with a minimal follow-up protocol failed to show a significant survival benefit the question arises whether lung cancer follow-up with frequent CT scans might have a deleterious effect. Indeed, in an observational study of 1294 NSCLC patients undergoing routine surveillance with CT scans, false-positive results led to additional testing in $25 \%$ of patients. Nevertheless, the rate of complications was rather low with $0.3 \%$ and no diagnostic associated deaths occurred [19]. On the other hand the NELSON lung cancer screening trial reported that a stringent diagnostic algorithm including nodule volume growth and volume doubling time improves the diagnostic accuracy and positive predictive value [20].

The National Lung Cancer Screening Trial evaluated health-related quality of life (HRQOL) in highrisk individuals undergoing screening for lung cancer either with CT scan or x-ray [21]. At baseline and 6 months of screening no significant differences in HRQOL or anxiety were observed in patients with a negative result compared to patients with a false positive scan. In contrast patients who were diagnosed with lung cancer due to screening reported lower HRQOL and anxiety at follow-up. These findings provide an indirect insight that lung cancer surveillance strategies might not pose significant psychosocial distress in patients after curative treatment for lung cancer.

Since guidelines suggested screening with chest $\mathrm{CT}$, the induction of radiation-induced lung cancer is another potentially harmful aspect of lung can- 
cer surveillance. According to an estimation of patients who underwent screening for lung cancer over 10 years in the COSMOS study only every 108th lung cancer detected by screening was attributed to radiation exposure [22]. Therefore, it can be assumed that even though the risk of radiation-induced lung cancer is not negligible, it might be of minor relevance.

\section{Discussion}

Despite the recommendation of CT scan based surveillance after curative lung cancer treatment by guidelines, evidence for this specific type of follow-up remains poor. The only randomized trial that has evaluated a maximal surveillance strategy including abdominal and chest CT scans with a minimal followup using thoracic X-rays failed to show a significant survival benefit after a median follow-up of 8.7 years [18]. The authors stated that a longer follow-up is necessary not to miss a potential long-term OS benefit of CT-scan-based surveillance. To the best of our knowledge, no further updates of the IFCT-0302 trial have been published since 2017. Indeed Kaplan-Meier curves seem to separate after a follow-up of approximately 7 years. Hence, it might be assumed that results are still immature to draw a final conclusion on the potential long-term effect of lung cancer surveillance.

At least in the setting of lung cancer screening, two sufficiently powered trials have shown that screening by chest CT leads to a reduction in lung cancer mortality in high-risk individuals. After a median followup of 6.5 years a $20 \%$ risk reduction of lung-cancerspecific mortality was observed in the CT scan arm compared to the X-ray arm of the NLST [2].

In the NELSON lung cancer screening study, comparable observations were made after a median follow-up of 10 years [20]. Since, the magnitude of patients undergoing curative treatment for lung cancer possess high-risk features for the development of second primary lung cancer, follow-up using CT scan seems to be reasonable in the light of positive lung cancer screening trials.

\section{Conclusion}

Even though, follow-up using CT scans after curative treatment for lung cancer is recommended by guidelines, no randomized trial so far has shown a beneficial effect of lung cancer surveillance using CT scans. Both strategies minimal and maximal follow-up are acceptable. Keeping in mind the low risk of harm of CT-scan based follow-up and potential curative salvage options in a small proportion of patients one might favour performing an intensified follow-up strategy. This strategy seems even more reasonable in the light of recently published results of lung cancer screening trials.
Moreover, comprehensive surveillance strategies including smoking cessation and evaluation of comorbidities to guarantee optimal follow-up of NSCLC patients is suggested.

\section{Take home message}

Even though, follow-up using CT scans after curative treatment for lung cancer is recommended by guidelines, no randomized trial so far has shown a beneficial effect of lung cancer surveillance using CT scans.

Keeping in mind the low risk of harm of CT-scan based follow-up and potential curative salvage options in a small proportion of patients one might favour performing an intensified follow-up strategy.

This strategy seems even more reasonable in the light of recently published results of lung cancer screening trials.

Funding Open access funding provided by University of Innsbruck and Medical University of Innsbruck.

Conflict of interest C. Ng, A. Pircher, F. Augustin, and F. Kocher declare that they have no competing interests.

Open Access This article is licensed under a Creative Commons Attribution 4.0 International License, which permits use, sharing, adaptation, distribution and reproduction in any medium or format, as long as you give appropriate credit to the original author(s) and the source, provide a link to the Creative Commons licence, and indicate if changes were made. The images or other third party material in this article are included in the article's Creative Commons licence, unless indicated otherwise in a credit line to the material. If material is not included in the article's Creative Commons licence and your intended use is not permitted by statutory regulation or exceeds the permitted use, you will need to obtain permission directly from the copyright holder. To view a copy of this licence, visit http://creativecommons.org/licenses/by/4.0/.

\section{References}

1. Ferlay J, Steliarova-Foucher E, Lortet-Tieulent J, Rosso S, Coebergh JW, Comber H, et al. Cancer incidence and mortality patterns in Europe: estimates for 40 countries in 2012. Eur JCancer. 2013;49(6):1374-403.

2. National Lung Screening Trial Research Team, Aberle DR, Adams AM, et al. Reduced lung-cancer mortality with lowdose computed tomographic screening. N Engl J Med. 2011;365(5):395-409.

3. Van Iersel CA, de Koning HJ, Draisma G, Mali WP, Scholten ET, Nackaerts K, et al. Risk-based selection from the general population in a screening trial: selection criteria, recruitment and power for the Dutch-Belgian randomised lung cancer multi-slice CT screening trial (NELSON). IntJCancer. 2007;120(4):868-74.

4. Oudkerk M, Devaraj A, Vliegenthart R, Henzler T, Prosch H, Heussel CP, et al. European position statement on lung cancer screening. Lancet Oncol. 2017;18(12):e754-e66.

5. Hu Y, McMurry TL, Isbell JM, Stukenborg GJ, Kozower BD. Readmission after lung cancer resection is associated with a6-fold increase in 90-day postoperative mortality. JThorac CardiovascSurg. 2014;148(5):2261-7.

6. Medbery RL, Gillespie TW, Liu Y, Nickleach DC, Lipscomb J, Sancheti MS, et al. Socioeconomic factors are associated 
with readmission after Lobectomy for early stage lung cancer. Ann Thorac Surg. 2016;102(5):1660-7.

7. FarjahF, BackhusLM, VargheseTK, MulliganMS, ChengAM, Alfonso-Cristancho R, et al. Ninety-day costs of videoassisted thoracic surgery versus open lobectomy for lung cancer. Ann Thorac Surg. 2014;98(1):191-6.

8. Harpole DH Jr, Herndon JE 2nd, Young WG Jr, Wolfe WG, Sabiston DC Jr. Stage I nonsmall cell lung cancer. A multivariate analysis of treatment methods and patterns of recurrence. Cancer. 1995;76(5):787-96.

9. Walsh GL, O'Connor M, Willis KM, Milas M, Wong RS, Nesbitt JC, et al. Is follow-up of lung cancer patients after resection medically indicated and cost-effective? Ann Thorac Surg. 1995;60(6):1563-70.

10. Hung JJ, Hsu WH, Hsieh CC, Huang BS, Huang MH, et al. Post-recurrence survival in completely resected stage I non-small cell lung cancer with local recurrence. Thorax. 2009;64(3):192-6.

11. Voltolini L, Paladini P, Luzzi L, Ghiribelli C, Di Bisceglie M, Gotti G. Iterative surgical resections for local recurrent and second primary bronchogenic carcinoma. Eur J Cardiothorac Surg. 2000;18(5):529-34.

12. Hamaji M, Allen MS, Cassivi SD, Deschamps C, Nichols FC, Wigle DA, et al. Surgical treatment of metachronous second primary lung cancer after complete resection of non-small cell lung cancer. J Thorac Cardiovasc Surg. 2013;145(3):683-90. discussion 690-1.

13. https://www.nccn.org/professionals/physician_gls/pdf/ nscl.pdf. Accessed 10 Jan 2020.

14. McAvoy S, Ciura K, Wei C, Rineer J, Liao Z, Chang JY, et al. Definitive reirradiation for locoregionally recurrent non-small cell lung cancer with proton beam therapy or intensity modulated radiation therapy: predictors of highgrade toxicity and survival outcomes. Int J Radiat Oncol Biol Phys. 2014;90(4):819-27.

15. Bar J, Ng D, Moretto P, Goss GD, Sun A, Macrae R, et al. Chemoradiotherapy for locoregional recurrence of nonsmall-cell lung cancer after surgical resection: a retrospective analysis. Clin Lung Cancer. 2013;14(2):200-4.

16. Lee J, Kim HK, Park BJ, Cho JH, Choi YS, Zo JI, et al. Recurrence dynamics after trimodality therapy (Neoadjuvant concurrent chemoradiotherapy and surgery) in patients with stage IIIA (N2) lung cancer. Lung Cancer. 2018;115:89-96.
17. Postmus PE, Kerr KM, Oudkerk M, Senan S, Waller DA, Vansteenkiste $\mathrm{J}$ et al. Early and locally advanced nonsmall-cell lung cancer (NSCLC): ESMO Clinical Practice Guidelines for diagnosis, treatment and follow-up. Ann Oncol.2017;28(suppl_4):iv1-iv21.

18. Westeel V, Barlesi F, Foucher P, Lafitte J, Domas J, Girard P, et al. Results of the phase III IFCT-0302 trial assessing minimal versus CT-scan-based follow-up for completely resected non-small cell lung cancer (NSCLC). Ann Oncol. 2017;28(suppl_5):v452-v449.

19. Lou F, Huang J, Sima CS, Dycoco J, Rusch V, Bach PB. Patterns of recurrence and second primary lung cancer in early-stage lung cancer survivors followed with routine computed tomography surveillance. J Thorac Cardiovasc Surg. 2013;145(1):75-81. discussion 81-2.

20. De Koning H, Van Der Aalst C, Ten Haaf K, et al. Effects of volume CT lung cancer screening: mortality results of the NELSON randomized-controlled population based trial. Abstract PL02.05. 2018 World Conference on Lung Cancer. 2018. Presented September 25, 2018.

21. Gareen IF, Duan F, Greco EM, Snyder BS, Boiselle PM, Park ER, et al. Impact of lung cancer screening results on participant health-related quality of life and state anxiety in the National Lung Screening Trial. Cancer. 2014;120(21):3401-9.

22. Rampinelli C, De Marco P, Origgi D, Maisonneuve P, Casiraghi M, Veronesi G, et al. Exposure to low dose computed tomography for lung cancer screening and risk of cancer: secondary analysis of trial data and risk-benefit analysis. BMJ.2017;356:j347.

Publisher's Note Springer Nature remains neutral with regard to jurisdictional claims in published maps and institutional affiliations.



